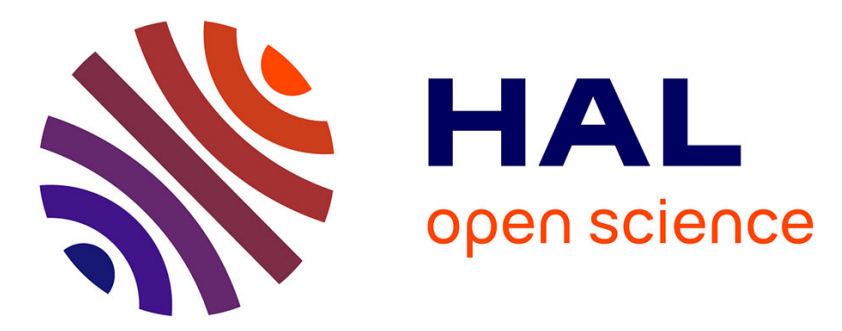

\title{
Silica-clay nanocomposites for the removal of antibiotics in the water usage cycle
}

\author{
Clément Levard, Karima Hamdi-Alaoui, Isabelle Baudin, Amélie Guillon, \\ Daniel Borschneck, Andrea Campos, Mohamed Bizi, Florence Benoit, Corinne \\ Chanéac, Jérôme Labille
}

\section{To cite this version:}

Clément Levard, Karima Hamdi-Alaoui, Isabelle Baudin, Amélie Guillon, Daniel Borschneck, et al.. Silica-clay nanocomposites for the removal of antibiotics in the water usage cycle. Environmental Science and Pollution Research, 2021, 28, pp.7564-757. 10.1007/s11356-020-11076-5 . hal-02989392

\section{HAL Id: hal-02989392 https://hal.science/hal-02989392}

Submitted on 5 Jan 2021

HAL is a multi-disciplinary open access archive for the deposit and dissemination of scientific research documents, whether they are published or not. The documents may come from teaching and research institutions in France or abroad, or from public or private research centers.
L'archive ouverte pluridisciplinaire HAL, est destinée au dépôt et à la diffusion de documents scientifiques de niveau recherche, publiés ou non, émanant des établissements d'enseignement et de recherche français ou étrangers, des laboratoires publics ou privés. 


\section{Silica-clay nanocomposites for the removal of antibiotics in the water usage cycle}

3

11 Marseille, France

\section{Abstract}

21 The increasingly frequent detection of resistant organic micropollutants in waters calls for better 22 treatment of these molecules that are recognized to be dangerous for human health and the

\section{*Corresponding author: levard@cerege.fr}

Keywords: micropollutant; sustainable treatment; clay nanohybrid, antibiotics, water usage cycle

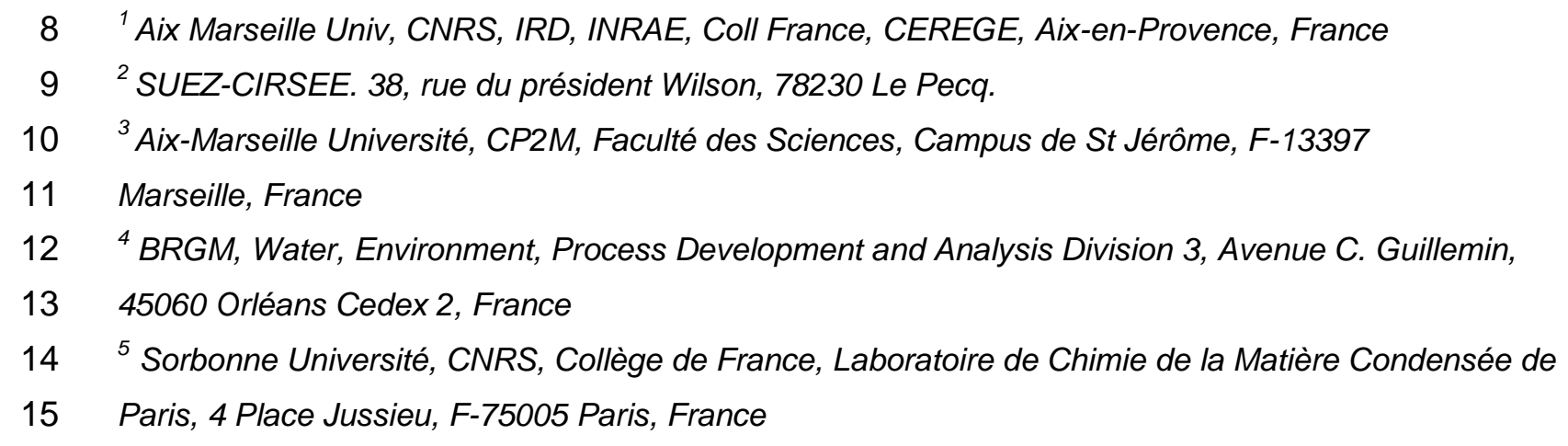

$12{ }^{4}$ BRGM, Water, Environment, Process Development and Analysis Division 3, Avenue C. Guillemin,

1345060 Orléans Cedex 2, France

$14{ }^{5}$ Sorbonne Université, CNRS, Collège de France, Laboratoire de Chimie de la Matière Condensée de

15 Paris, 4 Place Jussieu, F-75005 Paris, France 
31 thus a good candidate in terms of operating costs and environmental sustainability for the

32 removal of organic contaminants.

\section{Introduction}

34 Antibiotics are massively used in human and veterinary therapeutic applications. Their 35 production and use lead to increasing detection of antibiotics in the environment, especially in effluents from wastewater treatment plants, but also in surface water and even groundwater. The presence of these compounds in the water cycle can affect the quality of drinking water. The resistance of some of these compounds to the conventional processes applied in drinking water supply chains has been evidenced in several national surveys. For example, in the United States, a federal survey identified 118 pharmaceutical micropollutants at the outlet of 25 drinking water production plants (FURLONG et al., 2017).

In this context, it is indispensable to strengthen the monitoring and treatment of these

44 pharmaceutical pollutants at different stages of the water cycle. Two main treatment routes for pharmaceutical compounds are during the production of drinking water or during tertiary treatment of wastewater refining: the adsorption route and the chemical or biological oxidation route that were also widely explored for the elimination of other organic contaminants (PAVITHRA et al., 2019).

Activated Carbon (AC) is the most commonly used adsorbent medium for water treatment in industrial scale applications. The performance of $A C$ in retaining a large number of pollutants is undeniable but is nevertheless sometimes insufficient. A wide range of other media are currently available for direct or polishing water treatment, with different characteristics (origin, activity,

54 porosity, size, density, etc.). The best media for water treatment can be selected based on

55 these properties in order to optimize the removal of the targeted pollutant and to be integrated in 56 the existing treatment plant. On one hand, powdered activated carbon (PAC) in suspension can 57 be directly added to the water to be treated, which has the advantage of being flexible as the 58 dose can be adapted to the concentration of the pollutant. However, the main disadvantage of 59 PAC is its high operating cost when used continuously, and the difficulty involved in separating 60 the medium from the sludge or waste by settling or filtration at the disposal step. Granular 61 activated carbon (GAC), on the other hand, uses a fixed-bed filter, usually located in one or two 62 steps of the water treatment plant, for clarification and polishing. Compared with PAC, GAC is 
63 the most economical solution in larger systems or where organic contamination has to be 64 controlled continuously. GAC performance and treatment reliability for the removal of organics

65 are closely linked to the frequency of the carbon regeneration or replacement. In turn, the 66 frequency is highly dependent on the adsorption affinity of the pollutants and on competition 67 with the organic matter present in the water. This is particularly true with GAC used at the 68 clarification step (KNAPPE et al., 2003).

Considering the economic and technical limitations involved in the use of activated carbon in water treatment, developing an alternative process or material would be of great interest for water treatment suppliers. To be viable and applicable, such new processes should fulfill numerous conditions, including efficient pollutant elimination, easy integration into existing water

74 treatment plants as an additional refining step, easy removal from the treated water after use, 75 environmental sustainability, and low cost (PRASANNAMEDHA AND KUMAR, 2020).

76 Clay-based materials appear to be good alternative candidates in this context as they have a good adsorption capacity and ion exchange properties that can efficiently and selectively retain many micropollutants (BESNAULT et al., 2014; ZHU et al., 2016). Clays can be modified, e.g. by bridging or grafting nanoparticles, to increase the surface exchange by avoiding the stacking of the clay layers, to adjust the interlayer distance to the size of the targeted micropollutants and in turn, improve the performance and adsorption selectivity (LEE AND JANG, 1996; JOLIVET et al., 2004; HORNER et al., 2009; BANKović et al., 2013; BRINDLEY AND SEMPELS, 2018; GUÉGAN et al., 83 2020). In this work, we developed and tested clay-silica nanoparticle hydrid nanostructures that can be an economic alternative to the activated carbon conventionally used in water treatment. The

87 silica to clay ratio was adjusted to optimize the adsorption capacity of the nanocomposites (NCs). The efficiency of the resulting silica-clay NCs for the removal of ciprofloxacine was first tested on a model water. In the second step, real water contaminated by a selection of pharmaceutical micropollutants that are currently among the most recalcitrant to conventional

91 treatments used in industrialised countries was used to assess the performance of the different 92 NCs in realistic conditions. 


\section{Targeted pharmaceutical molecules}

95 The pharmaceutical substances studied here were chosen based on consumption, occurrence in the water cycle, recalcitrance to conventional treatments, and potential risk for the environment. Based on these criteria, four antibiotics, doxycycline, ciprofloxacin, danofloxacin and sulfamethoxazole, and an anticonvulsant, carbamazepine, were selected (Table 1).

Table 1. Main use and characteristics of the pharmaceuticals studied here

\begin{tabular}{|l|c|c|c|c|c}
\hline Pharmaceutical class & Antiepileptic & \multicolumn{3}{c}{ Antibiotics } \\
\hline Compounds & Carbamazepine & Ciprofloxacine & Danofloxacine & Doxycycline & Sulfamethoxazole \\
\hline Chemical formula & $\mathrm{C}_{15} \mathrm{H}_{12} \mathrm{~N}_{2} \mathrm{O}$ & $\mathrm{C}_{17} \mathrm{H}_{18} \mathrm{FN}_{3} \mathrm{O}_{3}$ & $\mathrm{C}_{19} \mathrm{H}_{20} \mathrm{FN}_{3} \mathrm{O}_{3}$ & $\mathrm{C}_{22} \mathrm{H}_{24} \mathrm{~N}_{2} \mathrm{O}_{3}$ & $\mathrm{C}_{10} \mathrm{H}_{11} \mathrm{~N}_{3} \mathrm{O}_{3} \mathrm{~S}$ \\
\hline Chemical structure & & &
\end{tabular}

103 The treatability of chemical compounds in water by adsorption on an hydrophobic medium, such as activated carbon, is often classified according to their respective log Kow (measurement of the differential solubility of chemical compounds in two different media), higher log Kow giving higher expected adsorption. Carbamazepine and sulfamethoxazole are thus expected to undergo strong adsorption, while ciprofloxacine is expected to adsorb more weakly, and danofloxacine and doxycycline should be less adsorbed. Performance tests have been carried out at laboratory, pilot and industrial scale for the elimination of carbamazepine (SUDHAKARAN et al., 2013; AKPINAR AND YAZAYDIN, 2017; BIZI, 2019; HE et al., 2020) and sulfamethoxazole

111 (STACKELBERG et al., 2007). Efficient removal of both compounds was obtained by adsorption 112 on PAC (MARGOT et al., 2013; BESNAULT et al., 2014).

113 AC is also well known as a non-specific but efficient treatment solution for removal of a wide 114 range of hydrophobic compounds in various matrixes (resources, drinking water, wastewater, 115 industrial effluents, etc.). However, the cost of $A C$ is high and finding les costly alternative media 116 is a real challenge for water treatment. That is why several works on different alternative 
117 adsorbent materials applied for micro-pollutants treatment have been undertaken. The materials 118 include clay-based media (YU et al., 2008; ZHANG et al., 2010) which have shown some 119 adsorption capacity. The elimination of ciprofloxacine has been studied at laboratory scale on 120 various media including carbon, clay, and zeolithes (WANG et al., 2015; LI et al., 2017; 121 Rostamian and BehneJad, 2017; BizI AND El BACHRA, 2020). However, these authors did not 122 study the application or the treatment efficiency of clay-based nanocomposites in realistic 123 conditions for the removal of several compounds with different solubility, size, hydrophobicity 124 and charge, such as the ones targeted here. Finally, few laboratory-scale studies on 125 danofloxacine and doxycycline treatments have focused on the difficulty of treating doxycycline 126 by adsorption (ALI AND AHMED, 2017; LIU et al., 2017).

\section{7}

128

129

\section{Nanocomposite synthesis}

The clay material used in this work was collected from Nador under the trade name Monador (North East Morocco, North Africa). It consists of a relatively pure $\mathrm{Na}$, Ca montmorillonite. The cationic exchange capacity of the raw clay sieved to $20 \mu \mathrm{m}$ was determined at $141 \mathrm{meq} / 100 \mathrm{~g}$. For this study, the finest fraction of the clay $(<2 \mu \mathrm{m})$ was recovered for the synthesis of the silica-clay NCs as follows: $20 \mathrm{~g}$ of the sieved clay were dispersed in $500 \mathrm{~mL}$ of ultrapure water by magnetic stirring at $500 \mathrm{rpm}$ for $24 \mathrm{~h}$. After 30 minutes, ultrasonic treatment was performed for 10 minutes. The clay suspension was then poured into a $25 \mathrm{~cm}$ glass column and left to settle for $20 \mathrm{~h}$. According to Stokes law and considering a clay density of $2.6 \mathrm{~g} \cdot \mathrm{cm}^{-3}, 20 \mathrm{~h}$ correspond to a sedimentation cutoff close to $2 \mu \mathrm{m}$ at $25 \mathrm{~cm}$ in height. The supernatant containing the size fraction below $2 \mu \mathrm{m}$ was recovered and freeze dried, for further preparation.

The silica nanoparticles used in this work were obtained from "Clariant Corporation" under the trade name $\mathrm{Klebosol}^{\circledR} 30 \mathrm{R} 50$. They were characterised by a primary particle size of $80 \mathrm{~nm}$ (BIzl, 2012), also confirmed in hydrodynamic size in pure water measured by dynamic light scattering $(82.4 \pm 0.6 \mathrm{~nm})$.

Silica-clay nanocomposites (NCs) were synthesized as follows. Clay was dispersed in Milli-Q water at a concentration of $20 \mathrm{~g} / \mathrm{L}$. The suspension was stirred for $24 \mathrm{~h}$ at $500 \mathrm{rpm}$ to favor layer exfoliation. Then, a volume of $\mathrm{SiO}_{2}$ nanoparticles was added to the suspension to reach 5 or 50 wt $\%$ of the clay substrate. At this neutral $\mathrm{pH}$, both clay and silica are negatively charged and are stable in suspension. The mixture was homogenized by magnetic stirring for one minute, and then immediately frozen in liquid nitrogen to maintain the homogenous distribution of silica and 
clay components. Water was then removed by freeze drying, and the recovered solid material was heated at $500^{\circ} \mathrm{C}$ for 4 hours to consolidate the architecture of the aggregates. In order to obtain material reference, separate pure silica and clay materials were also heated at $500^{\circ} \mathrm{C}$ for comparison with $\mathrm{NCs}$ referred as $\mathrm{SiO}_{2}-\mathrm{NP}-500^{\circ} \mathrm{C}$ and Clay- $500^{\circ} \mathrm{C}$.

\section{Characterization of the materials}

Scanning electron microscopy (SEM) analysis was carried out using a Zeiss Gemini 500 high resolution field emission scanning electron microscope equipped with an in-lens secondary electron detector. Images of uncoated samples were acquired at low voltages for surface sensitivity and also to avoid beam damage. X-ray diffraction (XRD) analysis was performed using a Panalytical X'Pert Pro diffractometer running at $40 \mathrm{kV}$ and $40 \mathrm{~mA}$ equipped with Co $\mathrm{K} \alpha$ radiation $(\lambda=1.79 \AA$ ). Samples were deposited on low background silicon plates and scanned in a $2 \theta$ range of $4-75^{\circ}$ with a step size of $0.033^{\circ}$ and a time step of $5.1 \mathrm{~s}$.

\section{Removal efficiency of ciprofloxacin in a model effluent}

163 Elimination of ciprofloxacin from a model effluent was studied as a preliminary approach to 164 optimize the synthesis of the sorbent material. Evian water $(\mathrm{pH}=7.5-7.8)$ was used to mimic the 165 ionic composition of a typical surface water. Ciprofloxacin in the aqueous medium was 166 quantified by measuring the specific absorbance peak at $272 \mathrm{~nm}$ wavelength. A Jasco V-650 167 UV-visible spectrophotometer (Jasco, Japan) was used for this purpose, with quartz cells of 1 $168 \mathrm{~cm}$ optical pathway. A calibration curve was first measured showing good linearity from 0.5 to $16920 \mathrm{mg} / \mathrm{L}\left(R^{2}=0.9999\right)$. Every absorbance measurement was processed in triplicate. 170 Ciprofloxacin was first spiked into water at $5 \mathrm{mg} / \mathrm{L}$. The sorbent material was then added at a 171 concentration of $50 \mathrm{mg} / \mathrm{L}$ and the reactor was kept under agitation for three hours by magnetic 172 stirring at $650 \mathrm{rpm}$. Aliquots of the mixture were sampled at different times and filtered at 0.45 $173 \mu \mathrm{m}$ to remove the sorbent material and the retained ciprofloxacin. The supernatant was then 174 analysed by UV absorbance to measure the concentration of ciprofloxacin remaining free in 175 solution. X-ray Photoelectron Spectroscopy (XPS) was performed using a Kratos - Axis NOVA 176 XPS equiped with a monochromatic Al K $\alpha$ source to assess adsorption mechanism (150 Watts). 
178 After use as a sorbent material during a tertiary or polishing treatment step, the NCs should be 179 easily recovered from the liquid medium in an additional quaternary step before the treated 180 water is released. This can be achieved by the rapid sedimentation of the material in the liquid 181 batch when agitation is stopped, which depends on the size and density of the dispersed units.

182 Dispersion or sedimentation of the synthesized materials in aqueous medium was measured 183 using laser diffraction and turbidity profiles. Firstly, $200 \mathrm{mg} / \mathrm{L}$ of $\mathrm{NC}$ was introduced in Evian 184 water, that mimicked the ionic composition of a typical surface water, and maintained under 185 constant agitation by magnetic stirring for four hours. A Malvern Mastersizer 3000 (Malvern 186 Instruments, Worcester, UK) connected to the agitated system via a peristaltic pump in 187 recirculation mode was used to measure the size distribution of the different NCs over time. For 188 comparison with reference clay materials, the same procedure was used for pure 189 montmorillonite clay before and after calcination at $500^{\circ} \mathrm{C}$. Secondly, at $\mathrm{t}=4 \mathrm{~h}$, a $20 \mathrm{~mL}$ aliquot 190 of the medium was sampled under agitation and poured into the sedimentation tube. A 191 Turbiscan apparatus (Formulaction, Toulouse, Fance) was used to measure the turbidity profile 192 along the tube height according to time. Measurements were recorded every 25 sec during 30 193 minutes. The suspension clarification was analyzed via the intensity of the transmitted light 194 increasing with time, while the formation of sediments was measured via the backscattered light 195 intensity in the bottom of the tube (lower $1 \mathrm{~mm}$ ). A $2 \%$ relative increase was reasonably used to 196 distinguish the top of the solid deposit from the initial background backscattered by the liquid 197 suspension.

\section{Removal efficiency in real groundwater}

199 After optimization of the synthesis and tests of NCs efficiency in model water, clay-silica NCs 200 were tested in real groundwater spiked with the five selected micropollutants at realistic 201 concentrations. Activated carbon, currently used in conventional water treatment, was also 202 studied for the purpose of comparison.

203 Groundwater from the Paris region (France) was used for this experiment $(\mathrm{pH}=7.5$, dissolved 204 organic carbon: $1.5 \mathrm{mg} / \mathrm{L}$, UV absorbance at $254 \mathrm{~nm}=4 \mathrm{~m}^{-1}$, expressed as optical density). The 205 main chemical elements constituting the geochemical composition were analyzed. Results are 206 given in mg/L: Al (<0.05), Ca (72.4), K (3.3), Mg (8.59), $\mathrm{Na} \mathrm{(15.3),} \mathrm{P}(<0.05)$ and $\mathrm{Zn}(0.04)$. In 207 order to control the presence of residual pollutants in this groundwater before exposition, the 208 concentration of the five studied micropollutants was determined. Only carbamazepine and 
209 sulfamethoxazole were detected in the groundwater, at respectively 10 and $5 \mathrm{ng} / \mathrm{L}$, giving the 210 chemical background.

212 The five micropollutants ciprofloxacine, danofloxacine, doxycycline, carbamazepine and 213 sulfamethoxazole were spiked into water at individual concentrations of $2 \mu \mathrm{g} / \mathrm{L}$. The sorbent 214 material was then added to the medium at a concentration of $50 \mathrm{mg} / \mathrm{L}$, as processed in 215 preliminary tests on the model effluent, and the mixture was agitated continuously for $48 \mathrm{~h}$. 216 Filtration at $0.45 \mu \mathrm{m}$ on a glass fiber filter was then processed to remove the sorbent material 217 and other particulate matter from the liquid medium.

218 An analytical method was developed to quantify the targeted micropollutants in this matrix and 219 also in other complex waters (surface water, wastewater, etc.). Solid phase extraction on HLB 220 cartridge (Waters) at $\mathrm{pH} 3$ was performed. Then, after washing and drying, an elution was 221 realised with $5 \mathrm{~mL}$ methanol. Analyses were liquid chromatography coupled with mass 222 spectrometry. A triple quadrupole mass spectrometer, TSQ Quantum (Thermo Fisher Scientific) 223 equipped with a HSS T3 column $\left(\right.$ Waters $^{\circledR}$ ) was used. The mobile phase followed a 224 water/methanol gradient $+0.1 \%$ formic acid, circulating at a solvent flow rate of $200 \mu \mathrm{L} / \mathrm{min}$, with 225 an injected volume of $10 \mu \mathrm{L}$ and a temperature of $30^{\circ} \mathrm{C}$. Detection was achieved by two MS/MS 226 transitions in positive ionization mode with electrospray source. Quantification was performed by 227 internal calibration using compounds labelled with $\mathrm{D}$ or ${ }^{13} \mathrm{C}$. The limits of detection obtained 228 ranged between 1 and $5 \mathrm{ng} / \mathrm{L}$.

\section{Results}



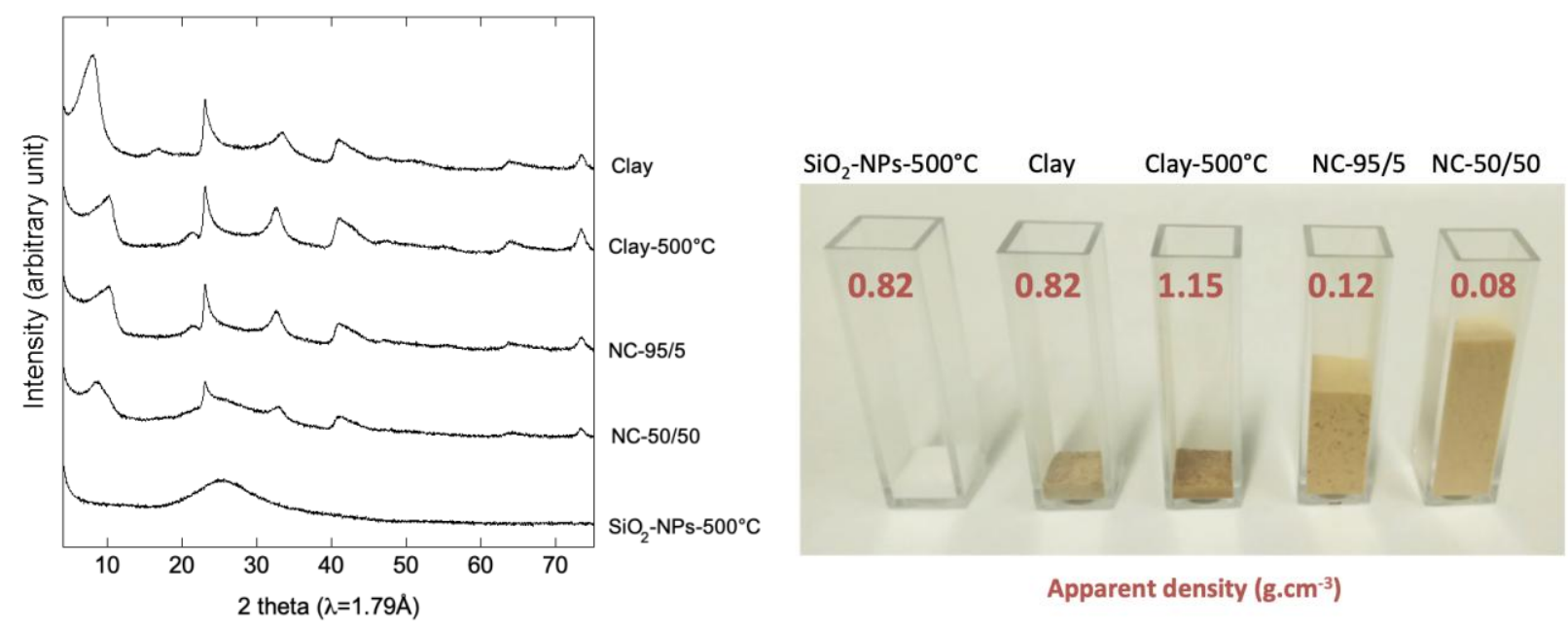

Figure 1. X-ray diffraction patterns (left) and apparent density measured in a volume of $230 \mathrm{mg}$ of material (right) of the initial clay, nanocomposites and references heated at $500^{\circ} \mathrm{C}$

Since silica is amorphous, the X-ray diffraction pattern of the clay-based materials is consistent with a montmorillonite (Figure 1, left). The first peak corresponds to the (001) reflection (basal spacing) and is characteristic of layer stacking. For raw clay, the interlayer distance is $12.5 \AA$, typical of hydrated Na-montmorillonite. When heated to $500^{\circ} \mathrm{C}$, the lamellar structure is preserved and the (001) reflection is shifted to $9.6 \AA$, indicating interlayer dehydration. Regarding NCs, although NC-95/5 was very similar to Clay- $500^{\circ} \mathrm{C}$, the first $\mathrm{NC}-50 / 50$ peak became less intense and broader with a slight shift at lower angles, suggesting increased disorder in layer

242 stacking and increased interlayer distance. However, no change in the order inside the layer 243 was observed. The increase in structural desorder is in good agreement with the measured 244 apparent density (Figure 2, right) that is more than one-order lower for NC-50/50 than for Clay$245500^{\circ} \mathrm{C}$ (decrease in the apparent density by a fator of 14). In addition, -although not observed by 246 X-ray diffraction, $5 \%$ of $\mathrm{SiO}_{2} \mathrm{Nps}$ in NC-95/5 is enough to strongly affect apparent density by 247 one order of magnitude compared to Clay $-500^{\circ} \mathrm{C}$. 

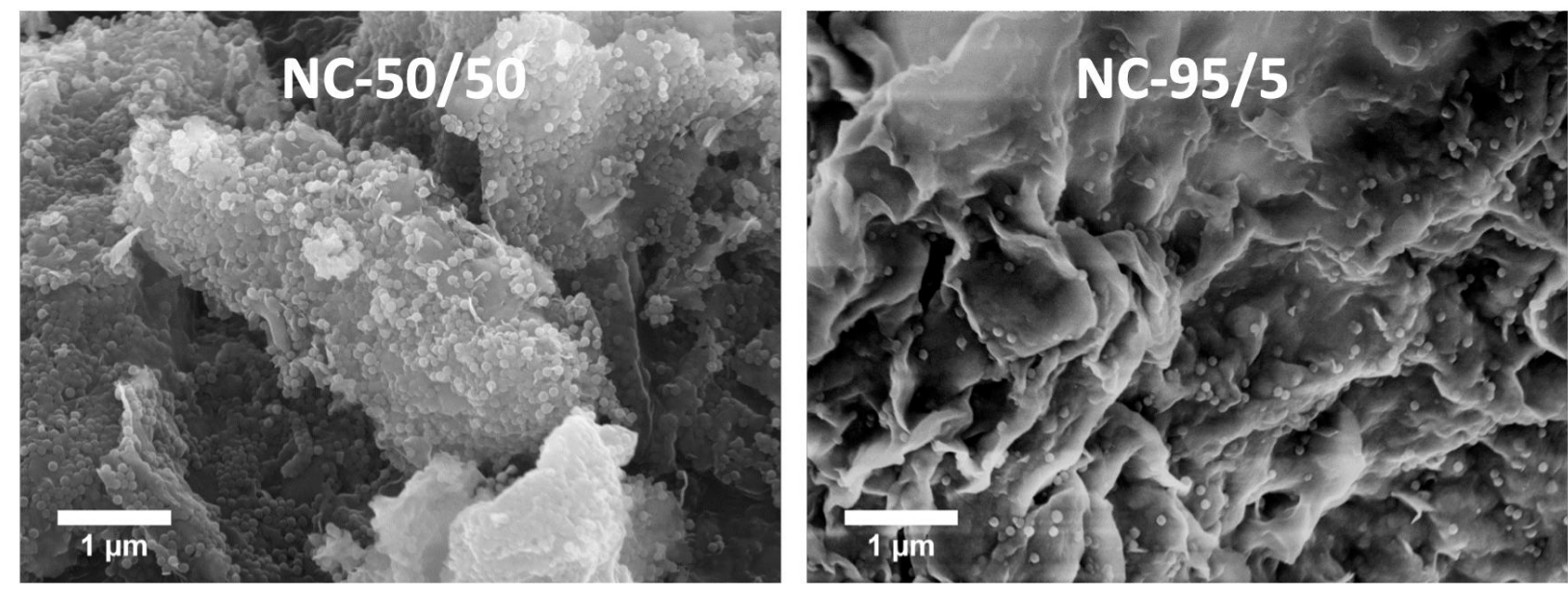

Figure 2. SEM images of NC-50/50 (left) and NC-95/5 (right)

SEM analysis was performed on NC-95/5 and NC-50/50 (Figure 2). Although SEM cannot provide evidence for the intercalation of $\mathrm{SiO}_{2}-\mathrm{NPs}$ in the interlayers, it can give an idea of the surface coverage and dispersion of $\mathrm{SiO}_{2}-\mathrm{NPS}$ at the surface of the clay sheets. For the lowest loading of $\mathrm{SiO}_{2}$-NPs (NC-95/5)(Figure 2, right), NPs are well-dispersed in the clayey matrix and are isolated from each other while NC-50/50 (Figure 2, left) exhibits a relatively high surface coverage of the $\mathrm{SiO}_{2}-\mathrm{NPs}$ at the clay surface. The randomly dispersed distribution of the $\mathrm{SiO}_{2}$ NPs observed on the clay substrate for NC-95/5 confirms that the method of preparation used here satisfactorily delivered an apparently homogenous hybrid material. Moreover, irregularities, microcavities and the non-compact and very porous nature of the observed structures in addition to the low apparent density (probable high macroporosity) will favor the rapid diffusion of water and micropollutants. Beyond these structural considerations, the reactivity of the NCs was assessed in both model effluents and in realistic conditions.

\section{Removal efficiency of ciprofloxacin in model effluents} spectroscopy. 


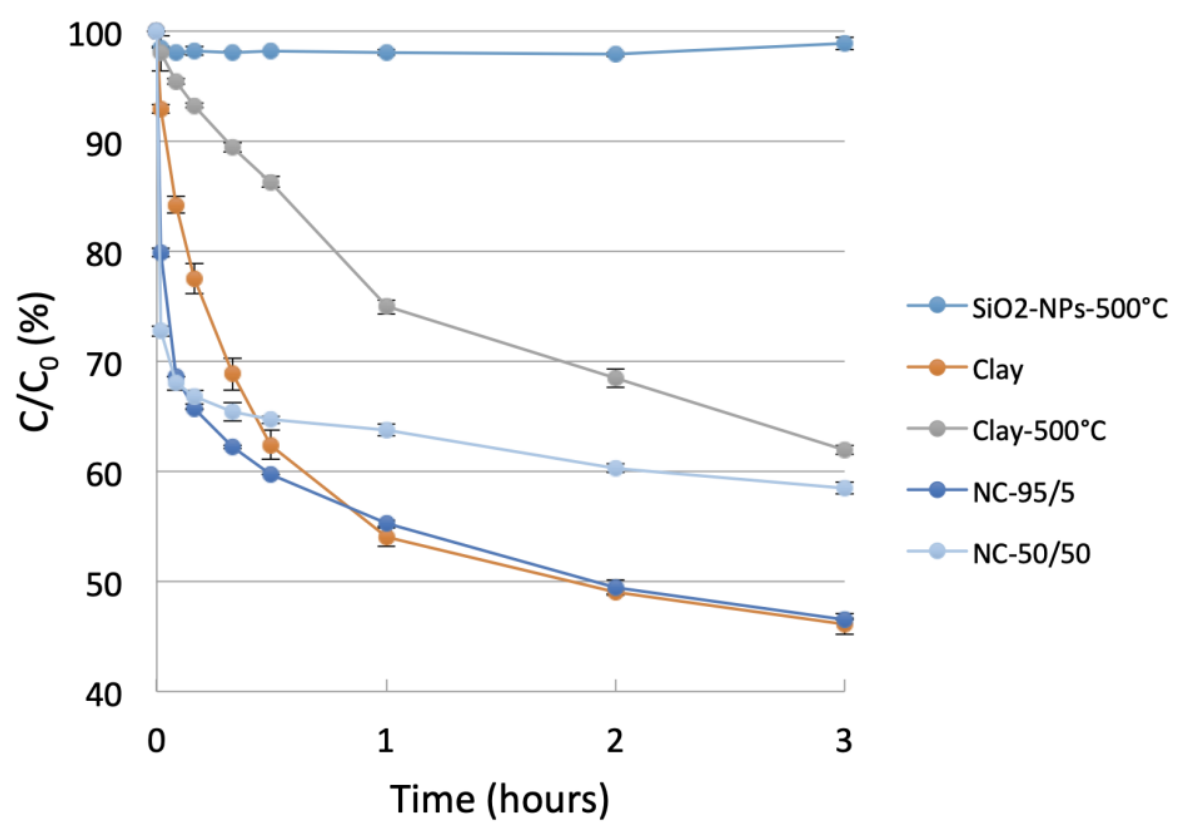

Time (hours)

272 Figure 3. Removal kinetics of ciprofloxacin from a model of surface water by adsorption to the sorbent materials: clay, $\mathrm{SiO}_{2}-\mathrm{NPs}-500^{\circ} \mathrm{C}$ and $\mathrm{NCs}$

275 The time-resolved removal of ciprofloxacin from the model water (Figure 3) provided insights 276 into the adsorption kinetics on clay (raw or heated at $500^{\circ} \mathrm{C}$ ), $\mathrm{SiO}_{2}-\mathrm{NPs}-500^{\circ} \mathrm{C}$ and $\mathrm{NCs}$. While 277 no removal of ciprofloxacin was obtained with $\mathrm{SiO}_{2} \mathrm{NP}-500^{\circ} \mathrm{C}$, significant but contrasted 278 adsorption behaviors were observed in clay and NC sorbents. The behaviors were 279 characterized by a first removal step lasting around 10 minutes, followed by a slower reaction 280 step that may correspond to saturation of the material. The slope of the curves measured over 281 the 10 first minutes (first 4 points) was used to obtain insight into the initial kinetic of the reaction 282 (Figure 4, blue bars). Three behaviors can be distinguished as (i) a rapid initial adsorption rate 283 with NC-95/5 and NC-50/50, (ii) a moderate initial adsorption rate obtained with clay and (iii) a 284 relatively slow adsorption rate with clay- $500^{\circ} \mathrm{C}$. Thus, the presence of $\mathrm{SiO}_{2}-\mathrm{NPs}$ in $\mathrm{NC}-95 / 5$ and 285 NC-50/50 significantly increased the adsorption kinetics of ciprofloxacin. 


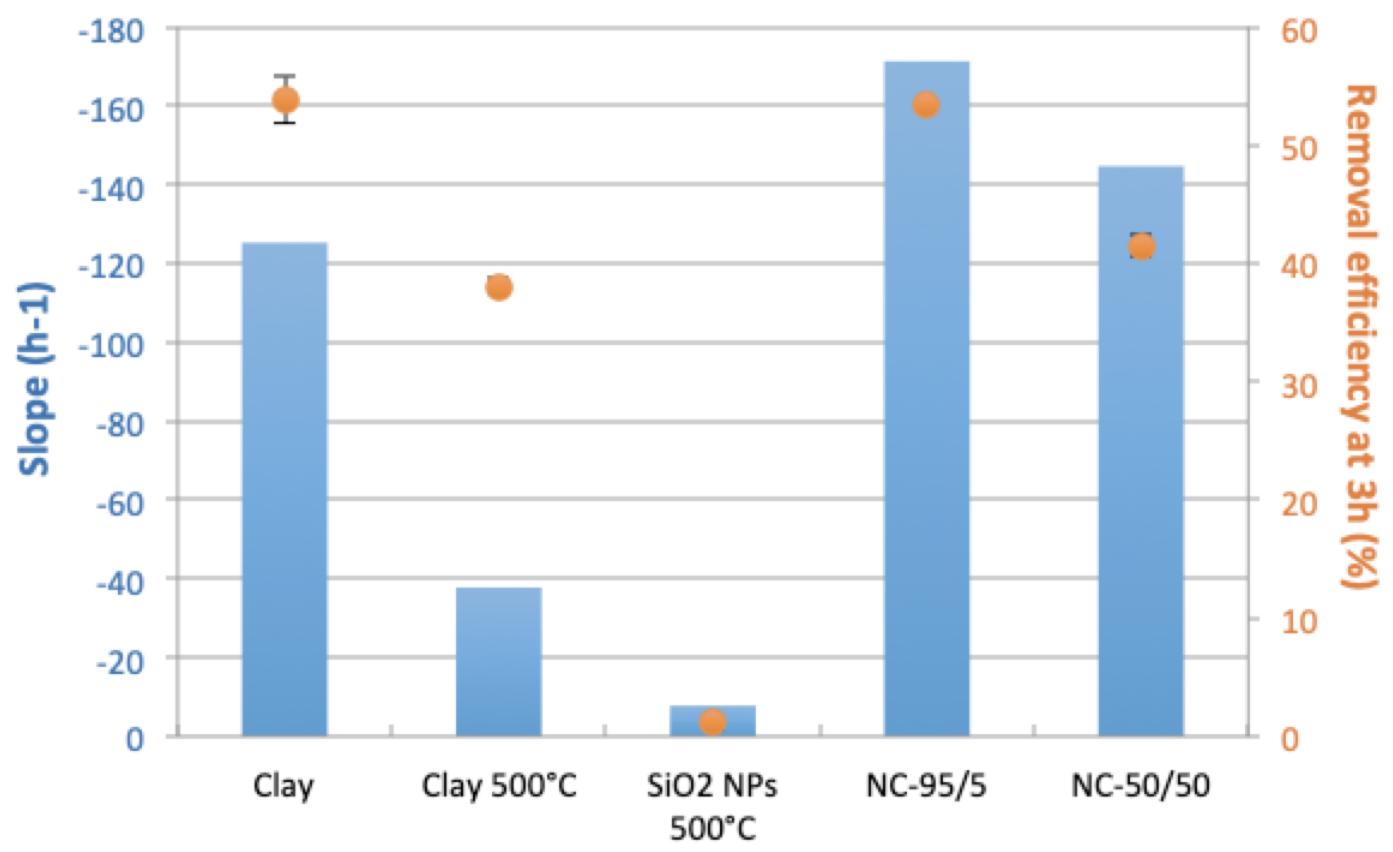

Figure 4. Removal kinetics (Figure 3) calculated on the first 4 experimental points (after 10 minutes of reaction) are represented on the primary y-axis (blue bars). Removal efficiencies after 3 hours are represented on the secondary y-axis (orange dots).

In addition to the initial kinetics, the removal efficiency measured after 3 hours provides insight into sorbent capacity (Figure 4, orange dots), which ranged from $1 \%$ for $\mathrm{SiO}_{2}-\mathrm{NPs}-500^{\circ} \mathrm{C}$ to $53.5 \%$ for clay and NC-95/5. The best results were obtained for raw clay and NC-95/5 with a removal efficiency $>50 \%$. Both products were well-hydrated after 3 hours and probably had similar surface areas and therefore similar adsorption capacity. This was not the case of NC50/50, which showed reasonable but lower removal efficiency than for NC-95/5 and clay that can be attributed to the high fraction of $\mathrm{SiO}_{2}-\mathrm{NPs}$ in the nanocomposite that has no affinity for ciprofloxacin, as shown in Figure 3.

The reason why NCs are more efficient sorbent material than clay $-500^{\circ} \mathrm{C}$ is certainly linked to the disordered and porous structure obtained in the NCs compared to clay- $500^{\circ} \mathrm{C}$, which is more favorable for fast diffusion of water and pollutants inside the material. In absence of NP inside the clay, the heating step at $500^{\circ} \mathrm{C}$ leads to sheet stacking that results in a dense structure that does not have the desired properties.

304 Although not responsive to ciprofloxacin, $\mathrm{SiO}_{2}-\mathrm{NPs}$ play a significant positive role in the kinetics 305 of ciprofloxacin adsorption. Based on kinetic and removal efficiencies, NC-95/5 appears to be 306 the most appropriate candidate for efficient removal of ciprofloxacin. Further analysis of the NC- 
307 95/5 sample was performed to check its crystallinity after adsorption of ciprofloxacin using XRD 308 and to assess adsorption mechanism using XPS.

310 The mineralogy of NC-95/5 is preserved after adsorption as shown in Figure S1. The (001) 311 reflection distance is shifted from $9.6 \AA$ (before adsorption) to $14.4 \AA$ (after adsorption). This 312 basal reflection observed after adsorption of ciprofloxacin is typical of hydrated Ca313 montmorillonite which is consistent with the fact that Evian water contains $80 \mathrm{mg} / \mathrm{L}$ of Ca ${ }^{2+}$. In 314 addition to NC-95/5, calcium carbonate phases were detected which is, once again, consistent 315 with the ionic composiiton of Evian water that contains bicarbonates $(360 \mathrm{mg} / \mathrm{L})$ which has 316 favored the precipitation of calcite and aragonite (Figure S1).

318 XPS analysis was performed on NC-95/5 before and after sorption of ciprofloxacine to 319 investigate sorption mechanism. However, although XPS confirms the presence of ciprofloxacin 320 on the NC-95/5 substrate (specific signature of Fluor), it does not allow to identify the sorption 321 mechanisms mainly because of the presence of a significant fraction of adventious carbon 322 classicaly observed in XPS measurements (see Figures S2, S3, S4 and S5 in SI).

324 In addition to surface reactivity, the recoverability of the particles after treatment is an important 325 aspect to be taken into consideration and was tested on the different sorbents NC-95/5,

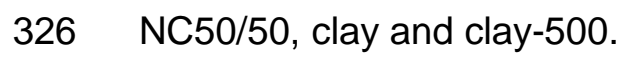




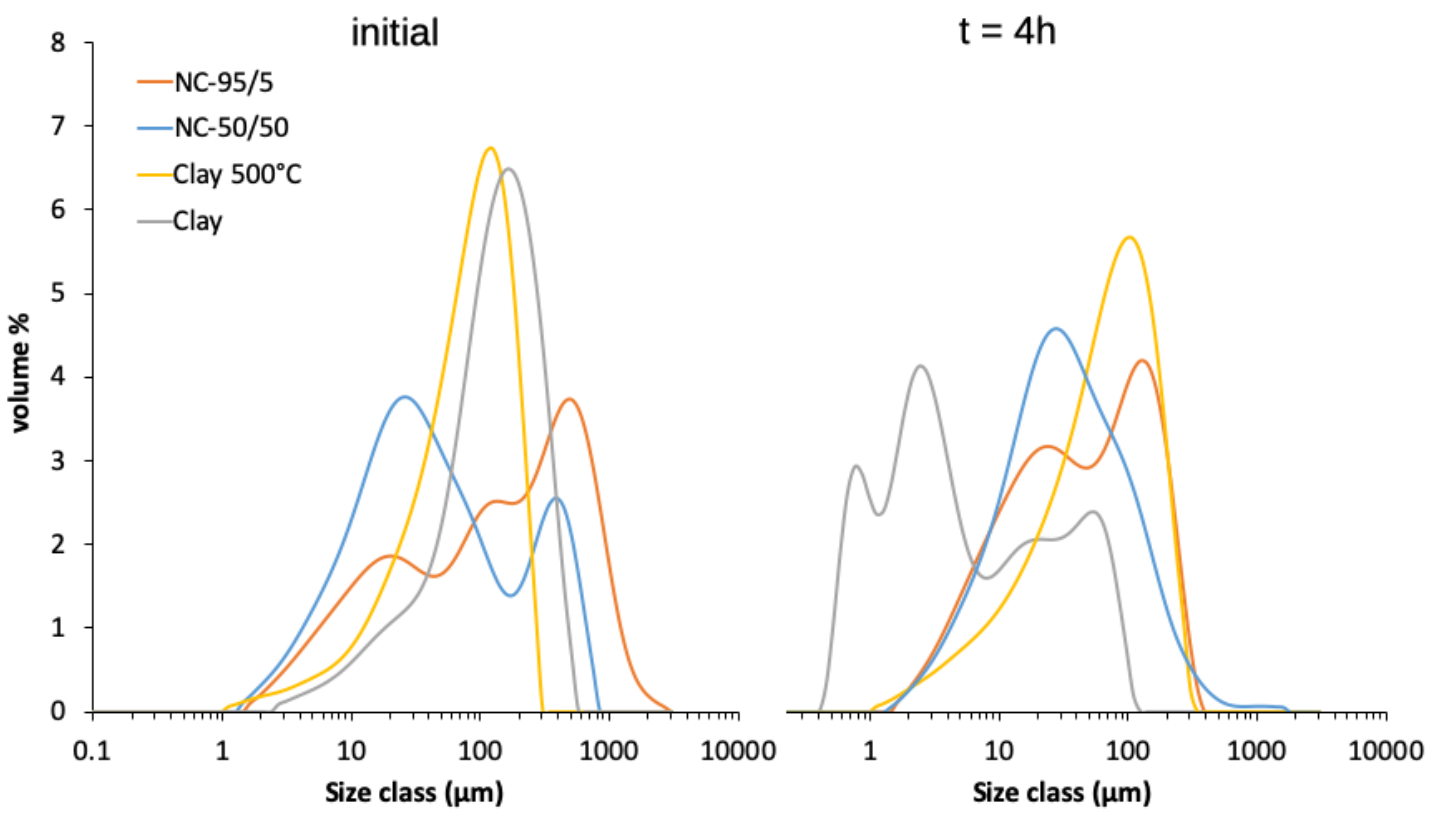

Figure 5: Size distribution of the clay and NCs in synthetic surface water, at $t_{0}$ (left, just after dispersion) and after $4 \mathrm{~h}$ of agitation (right).

Laser diffraction was used to measure the dispersion of the hybrid material in water compared to raw clay and to clay $-500^{\circ} \mathrm{C}$. It proved that heating at $500^{\circ} \mathrm{C}$ causes the formation of irreversible aggregates that can withstand the dispersion step in aqueous medium. Indeed, after $4 \mathrm{~h}$ of agitation in water, neither clay $-500^{\circ} \mathrm{C}$ nor the NCs displayed a particle size below $1 \mu \mathrm{m}$, which is roughly the upper limit of the colloidal size range. These three materials remained in an aggregated form with sizes ranging from 5 to $200 \mu \mathrm{m}$, while after $4 \mathrm{~h}$ of agitation, the clay was rapidly dispersed in sub-micrometer units. Colloidal dispersion of the montmorillonite clay 341 usually implies continuous swelling, due to hydration of the inter-lamellar cations toward multiple 342 layers of water molecules. Here the calcination step at $500^{\circ} \mathrm{C}$ led to dehydration of those cations 343 and shrinkage of the interlamellar space, which likely reduced access to the water molecules 344 from the outside when the material was redispersed in water. This resulted in the irreversible 345 aggregation of the clay particles with no noticeable difference between the NCs and the clay$346500^{\circ} \mathrm{C}$.

347 The larger aggregate size obtained here certainly favors more rapid sedimentation of the NCs, 348 which should facilitate recovery from the water treatment plant after use. This was confirmed by 349 the sedimentation trends shown in figure 6 . After $4 \mathrm{~h}$ of agitation of the materials in synthetic 350 surface water, the sedimentation rate was measured in terms of supernatant clarification and of 351 formation of a sediment layer. The NCs clearly showed the highest sedimentation rates, 
352 reaching $30-35 \%$ of average supernatant clarification in 30 minutes (Figure $6 \mathrm{~A}$ ). In comparison, 353 the pure clay, which still contained sub-micrometer dispersed units, sedimented at the lowest 354 rate, reaching only $15-20 \%$ in the same time period. Clay- $500^{\circ} \mathrm{C}$ displayed different 355 sedimentation behavior characterized by a higher rate in the first 5 minutes, followed by a 356 slower rate. This suggests coexistence of high-density aggregates that settled out rapidly, and 357 of lower density aggregates that remained in suspension longer. These respective behaviors 358 are corroborated by the formation of the sediment layer shown in Figure 6B. The change in 359 sediment height over time points to higher kinetics of the nanocomposites than of pure clay, 360 reaching approximately $0.7 \mathrm{~mm}$ for NCs compared with $0.35 \mathrm{~mm}$ in $30 \mathrm{~min}$ for pure clay. Again, 361 clay $-500^{\circ} \mathrm{C}$ underwent more rapid sediment formation in the first 5 minutes, after which the 362 process slowed down. It is important to note that the change in sediment height over time 363 results not only from the sedimentation rate but also from apparent sediment density. As the 364 NCs are characterized by lower apparent density than pure clay, the sediments formed are 365 expected to result in a thicker layer at a given mass of material. Such a contribution of the 366 material density cannot be distinguished from that of the sedimentation rate in Figure 6B.

367 Of note, in the water treatment, the sedimentation efficiency of particulate matter is usually 368 adjusted by the adding chemicals such as coagulants and/or flocculants. So any increase in 369 sedimentation caused by the sorbent material, as obtained in our case, could also lead to lower 370 chemical dosage and new sludge characteristics and behavior (more compact, easier to treat 371 and to dispose of). 

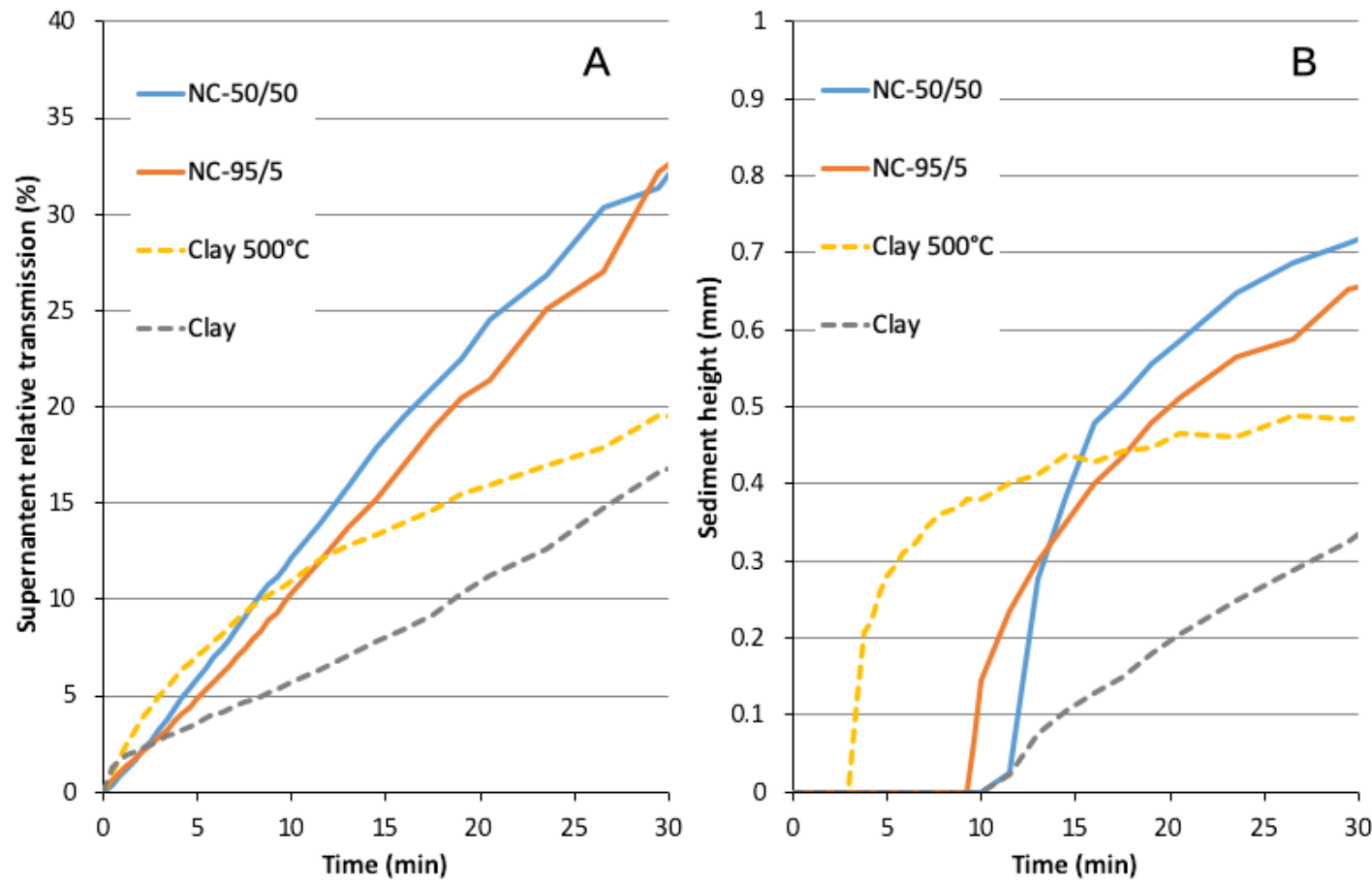

374 Figure 6: Kinetics of supernatant clarification (A) and sediment formation (B) measured

375 respectively by light transmission and backscattering in the upper $39 \mathrm{~mm}$ and bottom $1 \mathrm{~mm}$ of 376 the sedimentation tube for clay-based materials

377 4. Removal efficiency in groundwater

378 Table 2. Adsorption performances of the 5 micropollutants on activated carbon, NCs and the 379 reference materials

\begin{tabular}{|c|c|c|c|c|c|}
\hline $\begin{array}{l}\text { Sorbent } \\
(50 \mathrm{mg} / \mathrm{L})\end{array}$ & Cipro. & Dano & Sulfa & Doxy & Carba \\
\hline $\begin{array}{l}\text { Activated } \\
\text { carbon }\end{array}$ & $100 \%$ & $100 \%$ & $100 \%$ & $100 \%$ & $100 \%$ \\
\hline $\begin{array}{l}{\mathrm{MMT} / \mathrm{SiO}_{2}} \\
(50 / 50)\end{array}$ & $99 \%$ & $99 \%$ & $0 \%$ & $34 \%$ & $3 \%$ \\
\hline $\begin{array}{l}\text { MMT/SiO } \\
(95 / 5)\end{array}$ & $100 \%$ & $100 \%$ & $0 \%$ & $60 \%$ & $0 \%$ \\
\hline clay-500 & $94 \%$ & $95 \%$ & $0 \%$ & $41 \%$ & $0 \%$ \\
\hline
\end{tabular}




\begin{tabular}{|l|lllll|}
\hline $\begin{array}{l}\mathbf{S i O}_{2} \mathbf{N P}- \\
\mathbf{5 0 0}\end{array}$ & $0 \%$ & $0 \%$ & $0 \%$ & $11 \%$ & $0 \%$ \\
\hline
\end{tabular}

$382 \mathrm{SiO}_{2}-\mathrm{NPs}-500^{\circ} \mathrm{C}$ showed no reaction to the five micropollutants tested in this study. NC-95/5 383 and NC-50/50 removal efficiencies were ranked in the following decreasing order Ciprofloxacin $384=$ Danofloxacin $>$ Doxycycline $>$ Sulfamethoxazole $=$ Carbamazepine. Further mechanistic 385 studies are now needed to explain this trend. However, based on the chemical composition of 386 the different compounds, one can hypothesize that some properties may control the affinity 387 between NCs and organics. The two antibiotics that are efficiently removed by NCs are the only 388 ones that have a carboxylic functional group (Table 1), which is known to be a good complexing group, with pKa values of 5.86/8.24 and 6.07/8.56 for Ciprofloxacin and Danofloxacin, respectively. At neutral $\mathrm{pH}$, the carboxylic groups are deprotonated and most probably react with the positive Al groups of the clay (LABILLE et al., 2005). Na-Montmorillonite has also been shown to have good affinity for phenolic compounds (DJEBBAR et al., 2012), which may explain the relatively good removal efficiency of doxycycline. Finally, the last two contaminants that were not removed at all have neither carboxylic nor phenolic groups. They both have amino groups that were neutrally charged at the $\mathrm{pH}$ of our experiment. Adsorption of aniline (the phenyl group attached to an amino group) on Montmorillonite has been studied in the past and showed maximum adsorption when the $\mathrm{pH}$ of the solution was approximately equal to the $\mathrm{pKa}$ of the anilinium ion deprotonation reaction ( $\mathrm{pH}$ 4.5-5) (ESSINGTON, 1994). Minimum adsorption was observed at $\mathrm{pH}$ above 7 , which could partially explain the low affinity of clay for sulfamethoxazole and carbamazepine.

\section{Conclusion}

Silica-clay nanocomposites were designed specifically for the removal of antibiotics in potable water treatment plants as an alternative to powder activated carbon. Among the five pharmaceuticals tested, the silica-clay nanocomposites enabled efficient removal of three molecules, ciprofloxacin, danofloxacin and doxycyclin, making them promising sorbent materials. In the hybrid structure of the nanocomposites, although non-reactive, the $\mathrm{SiO}_{2}-\mathrm{NPS}$

408 are homogenously distributed and strongly affect clay stacking by creating disorder which 409 appears to favor the diffusion of water and micropollutants in the material. NC-95/5 showed the 
410 highest reactivity among the synthesized products. In addition, the design of the 411 nanocomposites includes a calcination step, which resulted in the formation of non-reversible 412 aggregates $>1 \mu \mathrm{m}$. After being used use as a sorbent in suspension, the material can thus 413 easily be recovered from the water using normal filtration or sedimentation techniques. Finally, 414 the use of natural clay is beneficial from an environmental point of view and the low loading of $415 \mathrm{SiO}_{2}$-NPs is advantageous in terms of the cost of synthesis.

416 As a possible next step in this work, NCs could be tested with other specific pollutants that are 417 not easily treated by activated carbon due to their unique properties (hydrophilic, polar, mobile, 418 small molecules), such as persistent and mobile organic compounds (PMOCs) (ARP et al., 419 2017). PMOCs, such as pesticide metabolites, per- and poly fluoro alkyl substances etc., are 420 sufficiently mobile in an aquatic environment to enter drinking water resources, and sufficiently 421 persistent to survive current water treatment processes. Treatment of such compounds is a real 422 challenge for environmental and sanitary risk management. Another possible perspective is to 423 increase the efficiency of $\mathrm{NCs}$ by replacing the poorly reactive $\mathrm{SiO}_{2}-\mathrm{NPs}$ by $\mathrm{Al}$ - or Fe-based $\mathrm{NPs}$ 424 that have a stronger affinity for these micropollutants. Finally, as an alternative to micropollutant 425 removal through adsorption, recent publications pointed to the interest of oxydoreductases 426 (such as peroxidases, polyphenol oxidases), hydrolases (such as proteases, esterases, lipases 427 and cellulases) and lyases for wastewater treatment and especially for the degradation of 428 phenol, aromatic compounds and hormones (DE CAZES et al., 2014a). The interest of using 429 laccases and esterases for the degradation of antibiotics has recently been demonstrated and 430 more generally, the biodegradation treatment by enzymes fixed on an adsorbent support like 431 clay or membrane has been proposed as promising treatment solution (MAGNAN et al., 2004; DE 432 CAZEs et al., 2014a; DE CAZES et al., 2014b; DE CAZES et al., 2015). In this perspective, NCs 433 could be used as a support for enzyme grafting. 
434 Ethics approval and consent to participate

435 Not applicable

436 Consent for pubication

437 Not applicable

438 Availability of data and materials

439 The datasets used and/or analysed during the current study are available from the

440 corresponding author on reasonable request.

441 Competing interests

442 The authors declare that they have no competing interests

\section{$443 \quad$ Funding}

444 This study was done within the framework of the POLPHARMA Project ANR-15-CE04-0007.

445 The authors gratefully acknowledge the French National Research Agency for financial support.

\section{Authors' contributions}

$447 \mathrm{CL}, \mathrm{IB}, \mathrm{AG}$ and JL have designed the experiment, $\mathrm{CL}, \mathrm{KH}-\mathrm{A}, \mathrm{DB}, \mathrm{AC}, \mathrm{IB}, \mathrm{AG}$ and JL have 448 performed the experiments, All authors have actively participated to the interpretation of the 449 data, writting of the manuscript and approved the final manuscript.

\section{References}


452

453

454

455

456

457

458

459

460

461

462

463

464

465

466

467

468

469

470

471

472

473

474

475

476

477

478

479

480

481

482

483

484

485

486

487

488

489

490

491

492

493

494

495

496

497

498

499

500

Akpinar, I., Yazaydin, A.O. (2017) Rapid and Efficient Removal of Carbamazepine from Water by UiO-67. Industrial \& Engineering Chemistry Research 56, 15122-15130.

Ali, M., Ahmed, M. (2017) Adsorption behavior of doxycycline antibiotic on NaY zeolite from wheat ( Triticum aestivum ) straws ash. Journal of the Taiwan Institute of Chemical Engineers 81, 218-224.

Arp, H.P.H., Brown, T.N., Berger, U., Hale, S.E. (2017) Ranking REACH registered neutral, ionizable and ionic organic chemicals based on their aquatic persistency and mobility. Environmental Science: Processes \& Impacts 19, 939-955.

Banković, P., Milutinović-Nikolić, A., Mojović, Z., Jović-Jovičić, N., Perović, M., Spasojević, V., Jovanović, D. (2013) Synthesis and characterization of bentonites rich in beidellite with incorporated Al or Al-Fe oxide pillars. Microporous and Mesoporous Materials 165, 247256.

Besnault, S., Ruel, S., Baig, S., Esperanza, M., Budzinski, H., Miege, C., Boucher, C., Menach, K., Coquery, M. (2014) Technical, economic and environmental evaluation of advanced tertiary treatments for micropollutants removal (oxidation and adsorption). ECOSTP (Verone, Italy),

Bizi, M. (2012) Stability and flocculation of nanosilica by conventional polymer. Natural Science 04, 372-385.

Bizi, M. (2019) Activated Carbon and the Principal Mineral Constituents of a Natural Soil in the Presence of Carbamazepine. Water 11, 2290-2306.

Bizi, M., El Bachra, F.E. (2020) Evaluation of the ciprofloxacin adsorption capacity of common industrial minerals and application to tap water treatment. Powder Technology 362, 323333.

Brindley, G.W., Sempels, R.E. (2018) Preparation and properties of some hydroxy-aluminium beidellites. Clay Minerals 12, 229-237.

De Cazes, M., Abejón, R., Belleville, M.-P., Sanchez Marcano, J. (2014a) Membrane Bioprocesses for Pharmaceutical Micropollutant Removal from Waters. Membranes 4, 692-729.

De Cazes, M., Belleville, M.P., Mougel, M., Kellner, H., Sanchez-Marcano, J. (2015) Characterization of laccase-grafted ceramic membranes for pharmaceuticals degradation. Journal of Membrane Science 476, 384-393.

De Cazes, M., Belleville, M.P., Petit, E., Llorca, M., Rodríguez-Mozaz, S., de Gunzburg, J., Barceló, D., Sanchez-Marcano, J. (2014b) Design and optimization of an enzymatic membrane reactor for tetracycline degradation. Catalysis Today 236, 146-152.

Djebbar, M., Djafri, F., Bouchekara, M., Djafri, A. (2012) Adsorption of phenol on natural clay. Applied Water Science 2, 77-86.

Essington, M.E. (1994) Adsorption of aniline and toluidines on montmorillonite. Soil Science 158, 181-188.

Furlong, E.T., Batt, A.L., Glassmeyer, S.T., Noriega, M.C., Kolpin, D.W., Mash, H., Schenck, K.M. (2017) Nationwide reconnaissance of contaminants of emerging concern in source and treated drinking waters of the United States: Pharmaceuticals. Science of The Total Environment 579, 1629-1642.

Guégan, R., De Oliveira, T., Le Gleuher, J., Sugahara, Y. (2020) Tuning down the environmental interests of organoclays for emerging pollutants: Pharmaceuticals in presence of electrolytes. Chemosphere 239, 124730.

He, Q., Liang, J.-J., Chen, L.-X., Chen, S.-L., Zheng, H.-L., Liu, H.-X., Zhang, H.-J. (2020) Removal of the environmental pollutant carbamazepine using molecular imprinted adsorbents: Molecular simulation, adsorption properties, and mechanisms. Water Research 168, 115164. 
501

502

503

504

505

506

507

508

509

510

511

512

513

514

515

516

517

518

519

520

521

522

523

524

525

526

527

528

529

530

531

532

533

534

535

536

537

538

539

540

541

542

543

544

545

546

547

548

549

550

Horner, O., Neveu, S., Montredon, S., Siaugue, J.-M., Cabuil, V. (2009) Hydrothermal synthesis of large maghemite nanoparticles: Influence of the $\mathrm{pH}$ on the particle size. Journal of Nanoparticle Research 11, 1247-1250.

Jolivet, J.-P., Chanéac, C., Tronc, E. (2004) Iron Oxide Chemistry. From Molecular Clusters to Extended Solid Networks. Chemical communications (Cambridge, England) 35, 481-7.

Knappe, D.R.U., Li, L., Quinlivan, P.A., Wagner, T.B. (2003) Effects of activated carbon characteristics on organic contaminant removal. Awwa Research Foundation, Denver, CO :.

Labille, J., Thomas, F., Milas, M., Vanhaverbeke, C. (2005) Flocculation of colloidal clay by bacterial polysaccharides: Effect of macromolecule charge and structure. Journal of colloid and interface science 284, 149-56.

Lee, D.C., Jang, L.W. (1996) Preparation and characterization of PMMA-Clay hybrid composite by emulsion polymerization. Journal of Applied Polymer Science 61, 1117-1122.

Li, S., Zhang, X., Huang, Y. (2017) Zeolitic imidazolate framework-8 derived nanoporous carbon as an effective and recyclable adsorbent for removal of ciprofloxacin antibiotics from water. Journal of Hazardous Materials 321, 711-719.

Liu, S., Xu, W., Liu, Y.-g., Tan, X., Zeng, G.-m., Li, X., Liang, J., Zhou, Z., Yan, Z.-I., Cai, X.-X. (2017) Facile synthesis of $\mathrm{Cu}(\mathrm{II})$ impregnated biochar with enhanced adsorption activity for the removal of doxycycline hydrochloride from water. Science of The Total Environment 592.

Magnan, E., Catarino, I., Paolucci-Jeanjean, D., Preziosi-Belloy, L., Belleville, M.P. (2004) Immobilization of lipase on a ceramic membrane: activity and stability. Journal of Membrane Science 241, 161-166.

Margot, J., Kienle, C., Magnet, A., Weil, M., Rossi, L., de Alencastro, L., Abegglen, C., Thonney, D., Chèvre, N., Schärer, M., Barry, D. (2013) Treatment of micropollutants in municipal wastewater: Ozone or powdered activated carbon? The Science of the total environment 461-462C, 480-498.

Pavithra, K.G., Kumar, P.S., Jaikumar, V., Rajan, P.S. (2019) Removal of colorants from wastewater: A review on sources and treatment strategies. Journal of Industrial and Engineering Chemistry 75, 1-19.

Prasannamedha, G., Kumar, P.S. (2020) A review on contamination and removal of sulfamethoxazole from aqueous solution using cleaner techniques: Present and future perspective. Journal of Cleaner Production 250, 119553.

Rostamian, R., Behnejad, H. (2017) A unified platform for experimental and quantum mechanical study of antibiotic removal from water. Journal of Water Process Engineering 17, 207-215.

Stackelberg, P., Gibs, J., Furlong, E., Meyer, M., Zaugg, S., Lippincott, R. (2007) Efficiency of Conventional Drinking-Water-Treatment Processes in Removal of Pharmaceuticals and Other Organic Compounds. The Science of the total environment 377, 255-72.

Sudhakaran, S., Maeng, S.K., Amy, G. (2013) Hybridization of natural systems with advanced treatment processes for organic micropollutant removals: New concepts in multi-barrier treatment. Chemosphere 92.

Wang, Y.X., Ngo, H.H., Guo, W.S. (2015) Preparation of a specific bamboo based activated carbon and its application for ciprofloxacin removal. Science of The Total Environment 533, 32-39.

Yu, Z., Peldszus, S., Huck, P.M. (2008) Adsorption characteristics of selected pharmaceuticals and an endocrine disrupting compound-Naproxen, carbamazepine and nonylphenolon activated carbon. Water Research 42, 2873-2882.

Zhang, W., Ding, Y., Boyd, S.A., Teppen, B.J., Li, H. (2010) Sorption and desorption of carbamazepine from water by smectite clays. Chemosphere 81, 954-960. 
551 Zhu, R., Chen, Q., Zhou, Q., Xi, Y., Zhu, J., He, H. (2016) Adsorbents based on montmorillonite 552 for contaminant removal from water: A review. Applied Clay Science 123, 239-258.

553 